School of Finance

University of St.Gallen

BEST LAND USE WITH NEGATIVE EXTERNALITIES:

DETERMINING LAND VALUES FROM RESIDENTIAL RENTS

ROLAND FÜSS

JAN A. Koller

Working PAPERS ON FinANCE No. 2017/05

SWISS INSTITUTE OF BANKING AND FINANCE (S/BF - HSG)

APRIL 2017 


\title{
Best Land Use with Negative Externalities: Determining Land Values from Residential Rents*
}

\author{
Roland Füss ${ }^{\dagger} \quad$ Jan A. Koller
}

April 1, 2017

\begin{abstract}
When land regulations are binding, then the land price per $\mathrm{m}^{2}$ is determined by the attractiveness of the location and the restrictiveness of the regulation. In the case of a maximum floor area ratio $\left(F A R_{\max }\right)$ restriction, the best use land price can be directly expressed as a function of the $F A R_{\max }$ and local amenities. We show theoretically and empirically how this approach can be used to determine land values from residential rents. From our empirical results, we derive two main sources for a monocentric structure of land prices. First, the location attractiveness of centrally located dwellings makes land prices more expensive. Second, on a regulatory basis, the $F A R_{\max }$ works as a multiplier for land prices. Because the $F A R_{\max }$ is high in central areas, land prices are inflated accordingly. Our model gives insight into determinants of urban land prices. In addition, it is a useful approach for land appraisal in urban regions.
\end{abstract}

JEL classification: $C 1, R 3, R 5$.

Keywords: Apartment rent; land use regulation; floor area ratio (FAR); land prices; monocentric structure.

*Acknowledgments: We have benefited from helpful comments from Zeno Adams, Martin Brown, Stefan Fahrländer, Pascal Gantenbein, Anders Österling, Daniel Ruf and to those who participated in the ERES 2016 conference in Regensburg, the 2017 Swiss Real Estate Research Congress, as well as the doctoral seminar at the University of St.Gallen.

${ }^{\dagger}$ Corresponding author: Swiss Institute of Banking and Finance (s/bf), University of St.Gallen, Unterer Graben 21, 9000 St. Gallen, Switzerland and Research Associate at the Centre for European Economic Research (ZEW), Mannheim, Germany; Phone: +41 (0)71 224-7055, Fax: +41 (0)71 224-7088; Email: roland.fuess@unisg.ch

${ }^{\ddagger}$ Swiss Institute of Banking and Finance (s/bf), University of St.Gallen, Unterer Graben 21, 9000 St. Gallen, Switzerland, Phone: +41 (0)71 224-7059, Fax: +41 (0)71 224-7088, Email: jan.koller@c-alm.ch. 


\title{
Best Land Use with Negative Externalities: Determining Land Values from Residential Rents
}

\begin{abstract}
When land regulations are binding, then the land price per $m^{2}$ is determined by the attractiveness of the location and the restrictiveness of the regulation. In the case of a maximum floor area ratio $\left(F A R_{\max }\right)$ restriction, the best use land price can be directly expressed as a function of the $F A R_{\max }$ and local amenities. We show theoretically and empirically how this approach can be used to determine land values from residential rents. From our empirical results, we derive two main sources for a monocentric structure of land prices. First, the location attractiveness of centrally located dwellings makes land prices more expensive. Second, on a regulatory basis, the $F A R_{\max }$ works as a multiplier for land prices. Because the $F A R_{\max }$ is high in central areas, land prices are inflated accordingly. Our model gives insight into determinants of urban land prices. In addition, it is a useful approach for land appraisal in urban regions.
\end{abstract}

JEL classification: $C 1, R 3, R 5$.

Keywords: Apartment rent; land use regulation; floor area ratio (FAR); land prices; monocentric structure. 


\section{Introduction}

In cities, land transactions are scarce, whereas rental price observations are naturally very frequent. For instance, in the city of Zurich, the number of land transactions in 2010 was 86, while the number of rental offers was 1,642 on one of the multiple listings service (MLS) used in this study. Moreover, at central locations, negative externalities arise from a high urban density. In this paper, we provide a unique approach that allows estimating land prices from rental prices. Real estate developers maximize their profits by producing residential floor area until the optimal floor area ratio $(F A R)$, defined as the total floor area divided by the lot size, is reached. Under such circumstances, i.e., when externality effects result from increased population density, an effective regulatory instrument restricts the urban density. A very direct regulatory instrument is the residential floor area permitted to be built per $m^{2}$ of land. We therefore introduce the concept of maximum floor area ratio $F A R_{\max }$, which is the maximum admissible floor area ratio for a building.

The maximum land floor area ratio $\left(F A R_{\max }\right)$ is a special type of land use regulation with a direct economic interpretation which can be used to determine land values from residential rental prices. For the real estate developer who sells and leases residential floor area, the $F A R_{\max }$ is a device limiting the optimal floor area he can produce on a fixed lot of land. Given an exogenous rent for the amenities associated with the location of the real estate developer's land lot, the $F A R_{\max }$ works as a multiplier of the total floor area rental profit. Under the assumption of an efficient rental market, the $F A R_{\max }$ must be capitalized into the land value. If public goods are non-rival, i.e., negative externalities do not exist, then the $F A R_{\max }$ will ceteris paribus be proportional to the land value. To test this hypothesis, we first formulate a theoretical model where $F A R_{\max }$ enters the land pricing equation proportionally. We then empirically estimate land values using apartment rents and finally test them against actual land transaction prices.

The theoretical underpinning of the model is the idea that local amenities should be weighted by the land lot size in a hedonic pricing model (see Parsons (1990)). For re- 
gions with homogeneous amenities, this implies that the interaction coefficients of regional dummies with land lot size reflect the variation of local per $m^{2}$ land prices. However, this is only feasible with binding land use regulation that prevents too much building activity on a land lot. Otherwise, the assumption of non-rival public goods is not realistic. If, however, a higher residential density is associated with negative externalities (e.g., congestion, noise, or pollution), then the effect of the $F A R_{\max }$ on land prices will not be proportional. In terms of the model, it follows that the marginal effect will be $F A R_{\max }^{\rho}$, with $\rho<1$.

We argue that land use restrictions are likely to be binding in urban areas. In this case, the land use regulations have a direct impact on the per $m^{2}$ land price. In particular, the interaction approach of locations with lot size can be used to determine land price variations. We empirically show how apartment rent data can be used to determine per $m^{2}$ land price. We therefore formulate a theoretical model in which the potential apartment rent is capitalized into land values. The resulting land values are the outcome of two main sources, which we denote as land qualities. The first land quality is the location value, which is the value associated with the local amenities. The second quality of land is the set of land use regulations, which determines the potential of the land to provide housing space. ${ }^{1}$ A vacant land lot is only valuable for the real estate developer if it is endowed with building rights. The less restrictive the building regulations are, the higher the value of the land.

The effect of general land use regulations on housing prices and land prices has been widely studied (e.g., Ihlanfeldt (2007) and Kok, Monkkonen, and Quigley (2014)). One of the main findings is that more restrictive land use regulation decreases land prices and increases house prices. Similarly to these results, we find that a less restrictive land use regulation has two opposite effects on land prices. First, due to negative externalities of density, it decreases the value of local amenities and in turn decreases the apartment rents.

\footnotetext{
${ }^{1}$ Also known as best use concept or potential ground rent mentioned in Smith (1979).
} 
Second, it increases land prices due to higher supply of floor space and in turn higher rent potential. The result is an increasing but diminishing effect of land use regulation on land values.

Our approach has several theoretical and practical implications. First, it allows appraising land lots in urban areas using apartment rents. Since apartment rents are typically frequent in urban areas where land transactions are rare, the approach is particularly useful for real estate developers and investors interested in the price for vacant land. In addition, the approach allows the estimation of the land value of properties with a structure built on it. This hypothetical land value is particularly important for tax purposes, where the property must be decomposed into the value of the land and the structure. Furthermore, as a by-product of the transformation of rents into land values, we estimate a capitalization rate that capitalizes residential rents into land prices. This allows us to make a smooth price prediction for land in terms of a land value surface, which is a benchmark for a series of practical applications and future research.

From a theoretical point of view, our model explains the spatial variation of land rents as well as apartment rents. We find that in urban areas, with binding land use restrictions, the land value reflects not only the location value, but to the same magnitude, the land use regulations. This finding is particularly important in understanding urban patterns. Based on the broad literature of urban rent models, we expect that land values are monocentric. Indeed, the land value surface reveals a highly monocentric pattern in land values in the study area. As a direct consequence of our model, this pattern has two main sources: The first and extensively studied determinant is the high attractiveness of centrally located floor area (i.e., location value). The second source is the regulation of the maximum local floor area ratio.

Based on an extensive data set of rental prices from the canton of Zurich, Switzerland, we show that the estimated land prices fit empirical land transaction prices quite well, with a correlation coefficient of 0.947 . As a by-product of the capitalization of apart- 
ment rents into land prices, we estimate a capitalization rate of $7.63 \%$. Further, we use the model to estimate a land price surface in the study region. We demonstrate that the monocentric structure of land prices has two sources: a monocentric maximum FAR restriction and a monocentric pattern of locational values.

The rest of the paper is organized as follows. Section 2 gives a brief overview of the related literature. Section 3 contains the theoretical model and introduces the methodology. The empirical results are presented in Section 4. Section 5 concludes and summarizes the most important results.

\section{Literature Review}

The novel approach in this study draws on and contributes to several strands of literature. First, it incorporates a concise land market into a house price model. ${ }^{2}$ In this respect, one of the few contributions is Parsons (1990), who suggests weighting local amenities with lot size in hedonic pricing models. We follow a conceptually similar approach because attributes related to location can be considered as public goods. On the other hand, more land implies more residential potential to consume the public good. While Parsons (1990) does not empirically test his theoretical findings, Fik, Ling, and Mulligan (2003) interact physical attributes (land area, floor area, and age) with locations (submarket dummies) in an empirical application. In contrast to our study, they do not account for land use regulation. Furthermore, we restrict the interaction of local amenities with lot size, while Fik, Ling, and Mulligan (2003) use a variety of different interactions. ${ }^{3}$

Second, we extract location values from apartment rent data. Rossi-Hansberg, Sarte, and Owens (2010) and Kolbe, Schulz, Wersing, and Werwatz (2012) estimate land prices

\footnotetext{
${ }^{2}$ Note that the focus of this study and of the literature we refer to is not about the dynamic interaction of the land and the housing market. However, our model has testable implications for the land and housing market on an aggregate level, e.g., the long-term relation between land and housing prices as in Ooi and Lee (2004).

${ }^{3}$ For instance, they find that interaction terms between age and location dummies can significantly explain variation in house prices.
} 
based on a spatially non-parametric approach. The former study estimates the impact of a residential urban revitalization program implemented in Richmond, Virginia, on land prices. They find that the program increased land prices by $2-5 \%$ per annum. Similarly to our study and conceptually inherited from Parsons (1990), they use per $m^{2}$ values, i.e., they weight location-related amenities by lot size. The latter study follows the same approach, however, the authors employ residuals from a regression of prices on physical attributes in order to predict location values. ${ }^{4}$ Cheshire and Sheppard (1995) estimate a related model for the per $m^{2}$ location value based on a data sample of only about 900 observations. The authors choose a more structured functional form allowing for multiple radial asymmetries. The main differences in this study are the way the location values capitalize into per $m^{2}$ land prices as well as the specification of the functional form in the spatial dimension. To our knowledge, Kolbe, Schulz, Wersing, and Werwatz (2012) is the only study that compares the estimated location values to land value benchmarks. Notably, they use expert-based land values and location ratings, whereas we compare the estimated land values with actual land transaction data.

Third, land use regulation is an aspect which has been widely studied in the literature. For instance, Quigley and Rosenthal (2008) give an overview of theoretical and empirical studies on housing regulation and propose a taxonomy of different regulatory instruments. Gyourko, Saiz, and Summers (2008) made a first attempt to standardize the extent of local regulatory environments in the US by providing an aggregated land use regulation index. In a recent empirical contribution Saiz (2010) argues that besides man-made regulatory restrictions, natural restrictions such as mountains and lakes play a crucial role for the supply of housing and house prices. None of these studies disentangles land values explicitly, but instead measures its aggregated impact on house prices. Our study considers the maximum floor area ratio $\left(F A R_{\max }\right)$ as a land use regulation with a simple economic interpretation. The reason is that the $F A R_{\max }$ is a direct measure of

\footnotetext{
${ }^{4}$ In this paper, we denote location value as the (total) location value per apartment, while the value per $m^{2}$ is denoted as land value.
} 
potential floor space as a function of land size. In contrast, none of the above-mentioned studies explicitly accounts for land quality in terms of the floor area ratio. ${ }^{5}$

Fourth, our approach enables the transformation of rent prices into land values. Besides the separation of rent prices for location and structure, this transformation requires the estimation of a capitalization rate. In our study this indicator emerges only as a by-product of the model test, while other studies (see, e.g., Sivitanides, Southard, Torto, and Wheaton (2001) and Chichernea, Miller, Fisher, Sklarz, and White (2008) for a more recent study) analyze the cross-section and time dimension of capitalization rates in the US housing market in more detail.

Finally, in our study we also examine the structural pattern of the resulting land prices and the $F A R_{\max }$. Our estimated land values as well as $F A R_{\max }$ show a monocentric pattern around the city center, i.e., we find a negative gradient in land prices as well as density. These findings support the basic theories of the monocentric city going back to seminal works by Muth (1969), Mills (1967) and Alonso (1964). However, instead of estimating a parametric model such as, e.g., Coulson (1991), we identify a monocentric structure based on a non-parametric approach.

\section{A Simple Land Value Model}

\subsection{Land Use Regulation}

In most countries, the use of land is, at least to some extent, regulated by local or national planning authorities. Quigley and Rosenthal (2008) give an extensive list and taxonomy of regulatory and non-regulatory instruments for land use planning. ${ }^{6}$ The common goal of many of these instruments is to regulate the population density within an area. In the

\footnotetext{
${ }^{5}$ In particular, the way Kolbe, Schulz, Wersing, and Werwatz (2012) account for land quality remains unclear.

${ }^{6}$ Non-regulatory instruments are measures that regulate settlement indirectly. For instance, the absence of public services and infrastructure leads to a low building density without regulatory measures.
} 
literature, there exist many empirical and theoretical studies on land use regulation and house prices. ${ }^{7}$ Most of these studies use a regulation index without a direct economic meaning. The restriction of the $F A R$ as a very explicit regulatory instrument for floor space is considered in very few studies. For instance, a theoretical contribution by Joshi and Kono (2009) suggests implementing both minimum and maximum FAR regulations to mitigate negative population externalities. Due to the time-varying nature of an optimal $F A R$, they propose a transition between minimum and maximum $F A R$. Barr and Cohen (2014) analyze the structure and the development of the FAR gradient in New York City from 1890 to 2009 and find that it exhibits a monocentric pattern. In this long-term perspective, however, they regard the $F A R$ as an (endogenous) outcome. Whether this outcome is the result of a binding land use regulation remains unclear. In contrast to the FAR measure, population density has been extensively studied from a theoretical perspective. ${ }^{8}$ In this context, the externality effects resulting from increased population density (e.g., congestion, noise, or pollution) have been of critical importance.

In this paper, the central focus is on the residential real estate developer's land use problem. We include the effect of negative externalities associated with a high urban density. Particularly, the intention of a real estate developer is to produce as much residential floor area as allowed on his own land. In that simplified context, the relevant regulatory instruments can be limited to those which directly affect the residential floor area permitted to be built per $m^{2}$ of land. Such a measure is defined as the total floor area divided by the lot size. Denoting floor area by $X$ and land area by $L, F A R$ is defined as:

$$
F A R \equiv \frac{\text { floor area }}{\text { land area }}=\frac{X}{L}
$$

\footnotetext{
${ }^{7}$ As Quigley and Rosenthal (2008) point out, a main issue in this field is the complexity of the actors involved with often ambiguous interests. Thus, identifying a causal structure, especially in a temporal context, is a very difficult task.

${ }^{8}$ See, e.g., Mulder (2006), Miles (2012), and Malpezzi (2013). For instance, Wheaton (1998) provides a theoretical analysis of land use with and without negative externalities. As such it is clearly the conceptual approach closest to ours.
} 
As a regulatory instrument, the local government can impose restrictive values on the $F A R$ for every lot of land. The most obvious way to impose such a restriction is to define a maximum floor area ratio $\left(F A R_{\max }\right)$. We are only interested in the maximum value, which allows introducing a cap on the local building density. We demonstrate that for real estate developers, the maximum restriction of the $F A R$ is a central figure working as a multiplier with respect to the rents gained from the land lot. In this respect, the $F A R$ is the developer's land quality, which differs from the size of the lot, denoted as land quantity. In our theoretical model, we assume best land use with binding regulation, i.e., the building exploits the land within its regulatory restrictions. Hence, it follows that

$$
F A R=F A R_{\max }
$$

for every lot of land. We refer to this equality as best land use with binding regulation. The assumption that this maximum $F A R$ is binding is reasonable in an urban area with a relative shortage in supply of residential floor space. ${ }^{9}$ The reason is that under a nonbinding maximum $F A R$, the real estate developer would simply build more floor space as long as the marginal profit is positive, i.e., if the costs associated with the physical structure are less than the expected rent revenue. In the canton of Zurich, the study area of this paper, the very low vacancy rate of $0.61 \%$ for apartments is a strong indicator of a shortage in supply of residential floor space. ${ }^{10}$ In addition, with the constant costs of physical structure, a non-binding $F A R$ would lead to a situation with equal marginal rent prices associated with the location (location rent). The empirical section will show,

\footnotetext{
${ }^{9}$ Rental apartments exclude owner-occupied apartments by definition. For this reason, the owners of rental apartments are real estate investors who own apartments for investment purposes. Typically, these kinds of real estate holders exploit land efficiently, i.e., fulfill the best land use concept. A debate related to the topic of this paper is the valuation of land under the best use assumption, originally initiated by Smith (1979) and his rent gap theory. For the interested reader, we refer to Hammel (1999) for a detailed discussion of the rent gap theory and its criticisms. The central and most important aspect for this study is that the actual use of land, i.e., the number of apartments built on the land, is closely related to the best use assumption.

${ }^{10}$ The apartment vacancy rate of $0.61 \%$ is the average in the canton of Zurich. However, the assumption that the maximum FAR restriction is generally binding requires a shortage in residential floor area in the entire region. Figure A.1 in the Appendix illustrates that this is indeed the case.
} 
however, that location rents largely vary.

For the apartment builder, it follows that for an additional $m^{2}$ of living area, $1 / F A R_{\max }$ of building land is required. The land use efficiency assumption implies that this relationship is always exactly fulfilled, i.e., no land is wasted and the maximum restriction is not violated. In order to build an apartment with living area $X$ (size), the builder thus requires total land area $L=\frac{X}{F A R}$. In a competitive developers' market, the assumption of best land use with binding regulation is plausible even in the context of negative externalities of population or building density. ${ }^{11}$

\subsection{Local Amenities}

The price of an apartment can be attributed to two kinds of amenities: physical attributes and local amenities. Locational attributes are by definition bound to the physical location of the apartment. Local amenities include, for instance, local taxation advantages, the household's relevant school districts, proximity to goods and services, as well as transport connections. While the physical structure could basically be a standardized unit, the location of the house or the apartment is always unique. From the household's perspective, the location of the land does not have a physical extent. In particular, amenities, provided externally in the form of public goods and associated with a particular location, are available independent of the size of the land. However, buying more land crowds out other potential bidders for the same location. It follows that the price of the location must somehow depend on the location quantity, i.e., the size of the land, which constitutes the location. As a consequence, the price of the location depends on the lot size. Thus, the

\footnotetext{
${ }^{11}$ Wheaton (1998), for instance, argues that local rent maximization is not necessarily the aggregate rent maximization.
} 
rental price must include a location value that depends on the size of the lot of land. ${ }^{12}$

The competitiveness of locations has its roots in the land market. We demonstrate how the value of amenities is reflected in the land price. Our model is based on and inherits its conceptual ideas from Parsons (1990). Consider a real estate developer ("developer", henceforth) who owns a parcel of land with total area $L_{T}$. The land exhibits constant local amenities. The developer can divide the land into $m$ lots of equal size. The local amenities associated with living on a lot of the developer are denoted by $A$. There is a construction firm from which the developer can borrow structure $X$ at the cost of $c(X)$. The developer can rent out each of the $m$ composite bundles (consisting of structure and land) for a rent $r(X, A, L)$. In this setting, the developer faces the profit maximization problem

$$
\max _{X, m}\{r(X, A, L) m-c(X) m\}
$$

Assume there exists an equilibrium characterized by a bundle $\left\{A^{*}, X^{*}, L^{*}\right\}$ with $L^{*}=\frac{L_{T}}{m^{*}}$, where $A^{*}$ is the equilibrium level of location-related attributes and $X^{*}$ the equilibrium structure attribute. The rent in equilibrium is therefore $r\left(X^{*}, A^{*}, L^{*}\right)$. The number of equally sized land lots $m^{*}$ follows directly from $m^{*}=L_{T} / L^{*}$.

Now suppose there is a potential renter who wants to rent an apartment on a lot of land that is a multiple $\left(\lambda L^{*}\right)$ of the standard lot size. In addition, he prefers a specific structure $\tilde{X}$. The builder would only sell the bundle $\{\tilde{X}, \tilde{A}, \tilde{L}\}$ if

$$
\begin{aligned}
& {\left[r\left(X^{*}, A^{*}, L^{*}\right)-c\left(X^{*}\right)\right]\left(m^{*}-\lambda\right)+r\left(\tilde{X}, \tilde{A}, \lambda L^{*}\right)-c(\tilde{X})} \\
& \geq\left[r\left(X^{*}, A^{*}, L^{*}\right)-c\left(X^{*}\right)\right] m^{*} .
\end{aligned}
$$

\footnotetext{
$\overline{12}$ Note that a particular lot of land does not only constitute location. It also has physical characteristics, of which the most important is the size of the lot. It is associated with two major non-location characteristics. On the one hand, the size of the lot restricts the ground floor of the structure. If a structure has only one floor, it is a direct restriction of apartment size. On the other hand, it should be noted that besides the lot size, the distinction between physical and locational amenities is also ambiguous for other attributes. For instance, the floor of an apartment has physical as well as location characteristics. Living on a higher floor increases the view but also the route from the building entrance to the apartment. However, these property characteristics are neglected in our study. We restrict the analysis on the size of the apartment and the land size necessary to provide that apartment size.
} 
If the cost and rent functions are linear, this condition can be simplified to

$$
r\left(\tilde{X}, \tilde{A}, \lambda L^{*}\right) \geq r_{X} \tilde{X}+\lambda r_{A} A^{*}+\lambda r_{L} L^{*}
$$

Under market competition, this must hold with equality and corresponds to the rental price of the bundle with the large lot size. The price of the bundle with the standard lot size $(\lambda=1)$ is $r\left(X^{*}, A^{*}, L_{A}^{*}\right)=r_{X} X^{*}+r_{A} A^{*}+r_{Z} L^{*}$.

\subsection{The Threefold Nature of Apartment Size}

Without loss of generality, we can set $L^{*}$ to unit size $\left(1 \mathrm{~m}^{2}\right.$, for instance). Then, $\lambda$ is the lot size in sqm. By rearranging the pricing equation, the general rental price function is written as

$$
r(X, A, \lambda)=X r_{X}+\lambda r_{Z}+\lambda A r_{A}
$$

This corresponds to the result derived by Parsons (1990), who suggests weighting local amenities by lot size. We now include the best land use with binding regulation, represented by Equation (2), which states that the best use lot size is $\frac{X}{F A R}$. The term $A r_{A}$ is the rent for a unit size location. Since we have set the unit size to 1 square meter, we can replace it by $r_{L}$, denoting the per $m^{2}$ land rent.

Further, we assume that the extent of the land only has a positive price if there remains a free space, which can be used, e.g., as a garden. ${ }^{13}$ The free space is the total land size minus the land occupied by the building. In our setting, the total land size is $\frac{X}{F A R}$ and the built land can be expressed as $\frac{X}{N L}$, where $N L$ is the number of levels of the building. The resulting free space $\left[\frac{X}{F A R}-\frac{X}{N L}\right]$ can be simplified to $X \frac{(N L-F A R)}{F A R N L}$. Using this concept of free space, we replace the corresponding price $r_{Z}$ by $r_{G}$, where $G$ refers to garden.

\footnotetext{
${ }^{13}$ Note that Parsons (1990) does not subtract the space required for the building.
} 
Therefore, the apartment rent can be written as

$$
r(X, A)=r_{X} X+r_{G} X \frac{(N L-F A R)}{F A R N L}+r_{L} \frac{X}{F A R}
$$

By taking the first derivative, the marginal effect of an additional $m^{2}$ in apartment size can be determined:

$$
\frac{\partial r(X, A)}{\partial X}=r_{X}+r_{G} \frac{(N L-F A R)}{F A R N L}+r_{L} \frac{1}{F A R}
$$

It follows that the marginal rent of an additional unit in apartment size is composed of three components. The first term is the price for an additional square meter of structure $\left(r_{X}\right)$, which is regarded as a globally constant structure price. The second term is the rent price for physical land $\left(r_{L}\right)$. Similarly to the structure rent, the value of this garden attribute is independent of the location. ${ }^{14}$ Finally, the third term in rent equation (8), $r_{L}$, is the rental price for the local amenities per land unit, reflected in the land price. The land price therefore consists of prices for two kinds of amenities: physical amenities associated with the garden and amenities associated with the location. Only the last term is directly associated with, and therefore, dependent on the apartment's location. In this study, we are interested in the land value, $r_{L}$, for a set of locations. ${ }^{15}$

\subsection{The Effect of Regulatory Changes on FAR}

In order to determine local land values, Equation (7) is estimated based on a hedonic regression model. To provide further interpretation of our theoretical results, we briefly outline the relationship between our exogenous and endogenous variables. Considering the third term in Equation (8) and assuming an apartment size $\bar{X}$, the total location price

\footnotetext{
${ }^{14}$ Note that the term garden is associated with a building's surroundings, not with the unusable land below the structure.

${ }^{15}$ This theoretical outcome allows us to empirically derive local land values from rental data in Section 4.
} 
per dwelling is

$$
r_{d}=r_{L} \frac{\bar{X}}{F A R}
$$

Depending on the temporal scope, we expect different and ambiguous effects. First, consider a rapid and substantial increase in the $F A R_{\max }$ in the whole urban area due to a regulatory change. This would increase the supply of floor area and therefore decrease the corresponding rent temporarily. From this perspective, land prices $r_{L}$ are exogenous, while location prices of dwellings $r_{L} \frac{X}{F A R}$ are endogenous. However, this change in the floor area rent will be capitalized into the equilibrium land value. Hence, it follows that rental prices are exogenous to the land values in the long run. This non-dynamic equilibrium can be analyzed cross-sectionally. In the empirical section, we estimate land rents using a global hedonic function with time dummy variables, i.e., a quasi-cross-sectional specification with estimated land rents representing average values for a region. Given a particular homogeneous region, the long-term demand for residential floor area is assumed to be highly elastic and therefore constant. With an endogenous land price, it is convenient to rewrite (9) as

$$
r_{L}=\frac{r_{d}}{\bar{X}} F A R^{\rho}
$$

by augmenting the floor area ratio with a negative externality parameter $\rho$. A change in the FAR directly capitalizes into land values. The parameter $\rho$ is the elasticity of the land price with respect to $F A R$ :

$$
\frac{\partial r_{L} / r_{L}}{\partial F A R / F A R}=\rho
$$

For instance, let us consider two lots of land of identical size and identical local amenities, e.g., due to their proximity. However, lot $A$ has a $F A R$ that is twice that of lot $B$. In the absence of negative externalities, the value of lot $A$ would be double the value of lot $B$. In the case with negative externalities, however, lot $A$ would be less than double the value of lot $B$, i.e., the $F A R$ has a decreasing marginal effect. Formally, we 
model this non-proportionality as $F A R^{\rho}$, with $\rho<1$.

The theoretical considerations concerning supply of and demand for floor area are illustrated in Figure 1. The best use assumption implies that the supply of floor area on a confined land lot is fixed, i.e., defined by the regulatory maximum $F A R$ restriction. The supply of floor area is therefore perfectly inelastic, unless the $F A R$ restriction changes. The demand for floor area in the short run is inelastic, represented by a downward-sloping demand curve. The long-term demand, however, is highly elastic (due to the presence of alternative locations) and is represented by a horizontal line. An increase in the supply of floor area (by increasing the $F A R$ ) is not supposed to change the price for floor area in the long run. With negative externalities, however, the higher density affects the demand for the local residential floor area in a negative way, illustrated as a decreasing long-term demand function.

\section{[INSERT FIGURE 1 HERE]}

\section{Empirical Results}

\subsection{Estimation Strategy}

In Subsection 3.2, we demonstrated that the value of land has a physical and locationrelated component. Assume the residential area is partitioned into $R^{k}$ subareas with $k=1 \ldots K$. The subareas are constituted by homogeneous local amenities, i.e., apartments exhibit the same local amenities within subareas. The resulting hedonic equation is

$$
r_{i}=\alpha+r_{G} L_{i}+r_{Y} Y_{i}+r_{X} X_{i}+r_{L}^{k} I\left(s_{i} \in R_{k}\right) L_{i}+\varepsilon_{i},
$$

where $Y_{i}$ is a vector containing general physical attributes (excluding apartment size) and $r_{Y}$ is the vector of corresponding rent prices. The location $s_{i}=\left\{\right.$ lat $\left._{i}, \operatorname{lon}_{i}\right\}$ is defined by the geographical coordinates of the apartment. The total rental price is a sum 
of the price for general physical attributes $p_{Y} Y_{i}$, the price for the physical apartment size $p_{X} X_{i}$, and the rental price for location $k$, given by $r_{L}^{k} I\left(s_{i} \in R_{k}\right) L_{i} . \quad I\left(s_{i} \in R_{k}\right)$ is an indicator function mapping locations to aggregated regions. ${ }^{16}$

In terms of rental market heterogeneity, this model states that there is only spatial heterogeneity in prices for locations. Spatial heterogeneity in hedonic pricing models has at least two different aspects. First, the heterogeneous structure of residuals leads to inconsistent estimates of pricing coefficients (see, e.g., Füss and Koller (2016)). Second, the residuals can be regarded as the price of unobserved property factors. With our model specification, we account for the spatial heterogeneity by finding an homogeneous area. However, it does not necessarily ensure consistent estimates of the hedonic pricing equation, but rather allows estimating the location values, which determine implicit land prices.

In order to estimate location prices, we need to differentiate between the physical and the locational land value. This is reached by including the interaction of homogeneous areas with land size:

$$
r_{i}=\alpha+r_{G} L_{i}+r_{X} X_{i}+r_{L}^{k, r}\left(L_{i} \times I\left(s_{i}\right)\right),
$$

where $I\left(s_{i}\right)$ denotes the indicator variable reflecting whether apartment $i$ is located in area $k$. The coefficients $r_{L}^{k, r}, k=1 \ldots K$, are the estimates for regional land rents, our parameters of interest. Note that the superscript $r$ in $r^{k, r}$ indicates that the estimation coefficients are relative rents since the intercept of the land rents cannot be identified from the interaction with region dummies. Hence, the model explains the spatial variation rather than the absolute level of land rents. The absolute land rent is therefore $r_{L}^{k}=$ $\delta+r_{L}^{k, r}$. This relationship is discussed in the next section.

Conclusions about the goodness-of-fit of the model can principally be drawn by

\footnotetext{
${ }^{16}$ The aggregation of single locations is necessary since land transaction price data is only available on a regional level.
} 
comparison of the model-predicted land values with actual transaction prices. However, it is also common to compare the goodness-of-fit with a benchmark model. Because in hedonic pricing models locational variation is often captured by location dummies, the location dummy model serves as our benchmark model. Formally, it can be written as follows:

$$
r_{i}=\alpha+r_{G} L_{i}+r_{X} X_{i}+r_{L}^{k, r} I\left(s_{i}\right) .
$$

Note that in this case, the parameter $r_{L}^{k, r}$ cannot be interpreted as a land rent per $m^{2}$. However, the location dummies have the potential to capture the variation in locational values.

\subsection{Transformation of Land Rents into Land Values}

In this section, we demonstrate how absolute land values $\left(p_{L}^{k}\right)$ can be estimated from relative, regional land rents $\left(r_{L}^{k, r}\right)$. Obviously, such a transformation must include a shift in levels (because rental prices are determined in relative terms) as well as a capitalization rule, which transforms rents into land prices. In order to keep the model tractable, we assume that a single (and constant) capitalization rate $d$ exists for all regions. Thus, the whole transformation can be formulated as

$$
p_{L}^{k}=\frac{r_{L}^{k^{r}}+\delta}{d}=\frac{\delta}{d}+\frac{1}{d} r_{L}^{k, r}
$$

where $\delta$ is the level coefficient to transform the relative rent into an absolute rent and $d$ is the capitalization rate. The term $\frac{\delta}{d}$ is therefore the level factor transforming the relative land price into the absolute land price. One possible approach is to make assumptions about $\delta$ and $d$, as well as about land price predictions. However, we use observed regional land price data to estimate these coefficients in order to test the validity of our implicit land price model. While model testing is the main purpose of our estimation strategy, we additionally arrive at an estimate for the capitalization rate as a by-product. 


\subsection{Data and Study Area}

Our empirical analysis covers an extensive data set for the canton of Zurich, Switzerland. In the canton of Zurich, the land use regulation is subsidiary to a national land use plan. The building law allows for a wide range of measures to "establish a foundation for human development." 17 This variety of instruments makes the consideration of individual regulatory measures impossible. We restrict our attention to the most important, and for our analysis sufficiently adequate, regulatory measure, the floor area ratio $(F A R)$. It is defined as the total living area $S_{T}$ divided by total lot area $L_{T} \cdot{ }^{18}$ In core areas, i.e., in city centers, the regional planning policy and building regulations typically allow a higher building density compared to rural areas.

The data source of the $F A R$ is the parcel data record provided by the statistical office of the canton of Zurich. The GIS data contains the location and shape of all land parcels in the canton of Zurich as well as the corresponding building rights and regulations. Using the coordinates of the rental data, the apartment's underlying land and its building rights can be determined. The rental price data we use stems from a multiple listings service (MLS) for apartment offerings from 2002 to 2014. Using rental data has the advantage that the number of observations is large. Property and vacant land transactions are sparse in the Zurich urban area; in fact, an overwhelming majority of households are renters. The share of owner-occupiers, for both houses and apartments, is about $7 \%$ in the central city. The advantage of the usage of rental data is that rental dwellings more often change hands, which results in a larger amount of data. Our data contains more than 40,000 observations from 2002 to 2014 including a wide set of apartment characteristics for the categories rental price, structure, location, and time, as shown in Table A.1 of the Appendix. The apartments come with a street address, which enables us to find

\footnotetext{
${ }^{17}$ Written in Planungs- und Baugesetz [planning and building law], §18, Abs.1.

${ }^{18}$ Defined in the Planungs- und Baugesetz [planning and building law] $\$ 254$ and in more detail in the Bauordnung der Stadt Zürich 2012 [building regulation of the city of Zürich 2012].
} 
coordinates using a geocoding service. ${ }^{19}$

Figure 2 shows a map of the canton of Zurich with the spatial dispersion of the observations represented by the dots, where light and dark colors represent low and high rents, respectively. The smallest jurisdictions are 171 communes, illustrated by solid shapes and listed in Table A.2 in the Appendix. The largest city in the canton is Zurich city, with a population of 383,708 at the close of 2013; the second largest city is Winterthur. In terms of population $(105,461)$, it is only about a quarter of the size of Zurich. ${ }^{20}$ The population in these two cities accounted for almost 35\% of the canton's total population $(1,421,895)$ at the end of 2013. In our data, $36 \%$ of the observations stem from Zurich and Winterthur, i.e., the data represents the dispersion of residents. Moreover, when comparing the data to BFS's 2012 nationwide household survey, we find that the rent prices of the apartments have representative mean values. For instance, in the canton of Zurich, the average rent price of an apartment with three rooms was 1,442 CHF, and 2,354 CHF for an apartment with four rooms ${ }^{21}$

\section{[INSERT FIGURE 2 HERE]}

To test the quality of our land model, we compare the estimated implicit land values to regional averages of land price transactions. The corresponding data is based on communal land registry offices, where all property transactions must be registered. For confidentiality reasons, only averages of these transaction prices are provided by the Zurich Statistical Office. ${ }^{22}$

\footnotetext{
${ }^{19}$ We used Google's geocoding API to translate street addresses into global coordinates. These coordinates are then transformed into Swiss Grid coordinates using transformation functions provided by Swisstopo.

${ }^{20}$ With regard to these population figures, the two cities are defined by the communes of Zurich and Winterthur.

${ }^{21}$ The corresponding average rent prices in the BFS nationwide household survey were 1,419 and 2,137 CHF. See BFS Strukturerhebung (2012) for more information.

${ }^{22}$ See Statistisches Amt des Kantons Zürich (2014).
} 


\subsection{Testing the Model}

In Section 3, we outlined how the relative rental price is transformed into absolute land prices. In order to identify the capitalization rate and the level coefficient in Equation (15), we need to make use of regional land prices. In this section, we test the model in two steps. In the first step, we estimate the model of relative implicit land rents, $p_{k}^{r}$, according to Equation (13). In the second step, these estimates are compared to observed regional land prices as suggested in Equation (15). To derive the coefficients $\delta$ and $d$, we run a regression of regional (aggregated) average land prices on our implicit relative land rents for the corresponding regions.

As mentioned above, the sparsity of vacant land transactions is one of the main reasons for the use of residential data to determine land values. For the same reason, however, we use averages of regional land transaction prices to test the predictive power of our model. A higher level of aggregation (i.e., larger regions) of land transaction prices has the advantage of increasing the sample and therefore improving the accuracy of mean land price estimates. The disadvantage is, however, that fewer (aggregated) observations are available to test its predictive power. This trade-off is restricted by the availability of data. We have access to regional mean prices for two regional aggregation levels: communes (171 communes) and consensus land use planning regions (12 regions). On the level of communes, the number of land transactions ranges from 0 to 26 , with an average of 2.6 transactions per commune and year. On the level of consensus land use planning regions, the corresponding range is from 16 to 72 , with an average of 40.5 transactions. Because we do not have observations for every commune in every year, the use of average land price transactions for communes is not suitable. For this reason, we have decided to use the pre-defined consensus land use planning regions to test the predictive power of the model.

Even though the time dimension is not of prior interest for our analysis, we include yearly time dummies to account for temporal effects. As a robustness test of our baseline 
model, we re-run the regression for different sub-periods and determine the capitalization rate for each sub-sample in order to identify its temporal development. The regression result of the first step is listed in Table 1. Besides the hedonic rental prices for different apartment characteristics, the coefficients represent the implicit relative land rents $\left(r_{L}^{k, r}\right)$ for regions 1 to $K$.

\section{[INSERT TABLE 1 HERE]}

For the interpretation of the first step regression, we choose two apartments from different regions and illustrate the meaning of the coefficients. The first apartment is located in the central city of Zurich with region ID $=261$. The annual rent for the apartment is 40,200 CHF. The floor area is $85 \mathrm{~m}^{2}$ and the regulatory maximum floor area on the land lot is $F A R_{\max }=130 \%$. The minimum required land size (efficient land size) to supply this floor area is $85 \mathrm{~m}^{2} / 130 \%=65.4 \mathrm{~m}^{2}$. The estimated coefficient of the efficient land size in region 261, i.e., the relative land rent, is $r_{L}^{261, r}=69.6 \mathrm{CHF}$. It follows that the incremental rent of the apartment associated with the required land amounts to $69.6 \times 65.4=4,551.8 \mathrm{CHF}$. The second apartment is located in the town "Uster" with region ID $=198$ and an annual rent of 20,200 CHF. With a floor area of $94 \mathrm{~m}^{2}$ and $F A R_{\max }$ of $65 \%$ the efficient land size is $94 \mathrm{~m}^{2} / 65 \%=144.6 \mathrm{~m}^{2}$. Given the relative land rent $r_{L}^{198, r}=-2.07 \mathrm{CHF}$, the incremental rent of the second apartment, associated with the required land, is $144.6 \times-2.07=-299.3 \mathrm{CHF}$.

We can now calculate the difference of the relative land rents of the two apartments, which amounts to 4551.8 CHF - (-299.3 CHF $)=4,851.1$ CHF. Hence, we estimate that the rent associated with the land of the first apartment is 4,851.1 CHF higher than that of the second apartment. In other words, the 4,851.1 CHF of the rent difference can be explained by differences in the attractiveness of the location combined with the difference in the required land consumption. In contrast to relative land rents, the coefficients of the physical characteristics are estimated globally, i.e. without having them interact with locations. For instance, the estimated annual price for a $m^{2}$ of floor area is $174.9 \mathrm{CHF}$. An 
important result is that the coefficient of the efficient land size is very small. This means that for the rental apartments in our data set, the rent associated with the "garden" is economically negligible.

In the second step, we compare the implicit relative land rents to the observed absolute mean land prices of the regions. Figure 3 shows the scatter plot of the two variables.

\section{[INSERT FIGURE 3 HERE]}

The strong linear dependence indicated by the graphical inspection is reflected in a high correlation coefficient of 0.947 between actual and predicted land values. We report the results for the fitted values according to Equation (15). Note that the number of observations in this regression is only $N=121$. The results of the linear regression of effective land prices on implicit land rents are summarized in Table 2. Columns (2) to (5) show the results of the interaction model, specified in equation (13). In columns (2) to (4), we perform the analysis for different sub-periods, while column (5) includes the main results for the whole sample period from 2002 to 2014 .

\section{[INSERT TABLE 2 HERE]}

For the whole time period, we conclude that our prediction of land price data is accurate. The high $R^{2}$ even on an aggregate level suggests high accuracy of the land prediction model. The result not only provides supporting evidence for our theoretical model, but also makes it feasible for practical applications. In other words, it shows how differences in local amenities finally capitalize into land prices. Also, the analysis of different sub-periods indicates that these results remain robust over time.

We compare the prediction of land prices with the location dummy model specified in equation (17), which serves as a benchmark model. Column (6) of Table 2 shows the corresponding prediction results. As the $R^{2}$ of the two models indicates, the goodnessof-fit of the interaction model is higher, and thus, outperforms the benchmark model. 
Note, however, that the difference in the $R^{2}$ is relatively small, which most likely can be traced back to the aggregation effect. The model predictions are tested against land prices of aggregate census regions. On this level of aggregation, the variation of the $F A R_{\max }$ is likely to be averaged out to some degree. Still, the goodness-of-fit is higher for the interaction approach.

As a by-product of the goodness-of-fit test, we report the level and slope coefficients in Table 2. The slope estimate of 13.110 corresponds to the inverse of the capitalization rate. The capitalization rate is therefore $1 / 13.110=7.63 \%$, which is relatively high compared to discount rates of real estate development projects. However, note that this capitalization rate is in gross term, i.e., the rent related to a land lot excludes the costs associated with the provision of a dwelling. In addition, since our analysis is restricted to the location value (rather than the value of physical characteristics), the capitalization rate corresponds to the location rent and location price, respectively. Presuming that the risk associated with the location of the real estate is higher than that associated with its structure, a high capitalization rate is not surprising. Concerning the temporal development, the capitalization rate strongly decreased from 2002 to 2014, with a capitalization rate of $5.68 \%$ for the recent sub-period 2010-2014. This is in line with a decreasing interest rate over this time period. ${ }^{23}$

A further identified parameter is the global negative externality parameter $\rho$. The parameter is obtained by maximizing the goodness-of-fit of the second step regression, i.e.,

$$
\begin{aligned}
& \min _{\rho} \sum\left(p_{L}^{k}-\frac{\delta}{d}-\frac{1}{d} r_{L}^{k, r}\right)^{2} \\
& \text { s.t. } \min _{\alpha, r_{X}, r_{G}, r^{k, r}} \sum\left(r_{i}-\alpha-r_{G} L_{i}-r_{X} X_{i}-r_{L}^{k, r}\left(\frac{X_{i}}{F A R^{\rho}} \times I\left(s_{i}\right)\right)\right)^{2}
\end{aligned}
$$

We estimate a value of $\rho=0.65$, which means that the $F A R$ is associated with

\footnotetext{
${ }^{23}$ As mentioned above, the coefficients of the location dummy model are not location rents. Therefore, the slope coefficient cannot be interpreted as capitalization rate.
} 
negative externalities. The goodness-of-fit of the second step regression (in terms of $R^{2}$ ) is shown in Figure A.2 in the Appendix. A negative externality parameter of 0.65 means that the effect of the $F A R$ on land prices is diminishing, e.g., the effect for a $F A R$ of 2 is $2^{0.65}$ or 1.569 .

\subsection{Land Value Surface}

In the previous section, we showed that the implicit land price model is able to fit land price transaction data accurately. As a by-product of this test, we estimated coefficients that allow us to predict land prices from implicit land rents. Based on these results, we can estimate a land value surface by smoothing the predicted (implicit) land values. For this purpose, we spatially generalize the rent function (12) to receive ${ }^{24}$

$$
r_{i}=\alpha+\phi L_{i}+\beta X_{i}+r\left(s_{i}\right) L_{i}+\varepsilon_{i}
$$

In particular, we run a non-parametric local regression of land price predictions (at individual level) on the longitude and latitude values. The model specification is based on the Nadaraya-Watson local constant estimator:

$$
\hat{r}\left(l o c_{h}\right)=N^{-1} \sum_{i=1}^{N} K_{h}, i\left(l o c_{j}\right) r_{i}
$$

where

$$
K_{h, i}\left(l o c_{j}\right)=\frac{K_{h}\left(l o c_{j}-l o c_{i}\right)}{N^{-1} \sum_{i=1}^{N} K_{h}\left(l o c_{j}-l o c_{i}\right)} \text { and } K_{h}(u)=h^{-1} K\left(\frac{u}{h}\right) .
$$

We use a Gaussian Kernel function $K($.$) , with a bandwidth h$, which is determined by cross-validation. As a result, we get a smooth surface of relative residential rents. Based on Equation (15), these estimates are transformed into land value estimates. The

\footnotetext{
${ }^{24}$ We follow the notations of Clapp and Wang (2006) for the specification of the hedonic pricing model.
} 
corresponding smooth land value surface is illustrated in Figure 4.

\section{[INSERT FIGURE 4 HERE]}

The predicted land prices for the canton of Zurich obtain a monocentric structure around the center of Zurich city. The gradient has not the same magnitude in every direction. Particularly, the slope of gradient is significantly lower along the lake. Besides the city of Zurich, different local elevations in land prices can be identified around the city of Winterthur.

In the next step, we demonstrate how the predicted land values of the canton of Zurich can be explained by major land attributes. First, note that the land price surface does, to some degree, smooth out the micro location. Therefore, it is primarily associ-

ated with macro location values. Our findings are largely in line with Kubli, Lüscher, Salvi, Schellenbauer, Schellenberg, Moser, Rey, and Bischoff (2008) and confirm that the macro location is indeed the most important determinant of land prices in this area. The corresponding land attributes are distance to CBD, tax level, and proximity to the lake. Because proximity to the lake is a matter of the larger environmental situation, we classify it as a macro location attribute as well. A closer look to the city of Zurich in Figure 4 illustrates in more detail the multi-radial monocentric land prices. The center is located next to the lake, very close to the CBD. As the contour lines indicate, land prices along the lakeside decrease much slower compared to all other directions.

\subsection{Dual Monocentric Structure}

We have argued from a theoretical perspective that the best use lot size is a promising measure for determining land values and have shown empirically that the predicted land values fit the actual data well. In particular, interacting the best use lot size with local amenities was successful for land price determination. In this section, we restrict the analysis to the larger urban area around the city of Zurich to demonstrate the monocentric 
structure of implicit land prices. As the main focus of this paper refers to the impact of land use regulation on land prices, we illustrate how the role of this regulation is reflected in the resulting monocentric pattern.

The predicted land value is the product of location value per $m^{2}$ and land quality. We can decompose these two factors and analyze them visually. First, we focus on the central location's attractiveness, which is reflected in the left panel of Figure 5. The graph shows a non-parametric surface of the location value, i.e., the part of a dwelling that reflects the value of the location. The CBD has the highest value and location prices are decreasing in all directions. However, the monocentric structure is distorted and irregular, with the lakeside naturally being the main source of irregularity for the location value. In summary, location values exhibit a monocentic structure, even without controlling for non-monocentric location amenities such as proximity to the lake.

Second, the fact that floor area ratios are higher in central areas increases land rents in the CBD. Because of the correlation between these two location characteristics (location attractiveness and $F A R$ ), the implicit land prices exhibit considerable variation. Indeed, the building regulation aims at a high $F A R$ in central locations, where the location value is already high. The obvious reason for this policy is to reduce prices for dwellings at favorable, central locations.

\section{[INSERT FIGURE 5 HERE]}

Finally, the predicted land values as the product of location quality and land quality are shown in Figure 6. The interaction of location value and location quality is embodied in this surface. The monocentric structure of land quality has clearly shaped the land price patterns into oval gradients. However, the pattern of the location values dominates the high value locations along the lakeside. In addition, the location value determines the center of the monocentric structure in land prices. Indeed, the highest land price is not in the CBD, but slightly more northward next to the lake. In that area, very high local 
amenities meet a relatively high floor area ratio, making it the most valuable land in the canton of Zurich.

\section{[INSERT FIGURE 6 HERE]}

\section{Conclusion}

In this paper, we showed that under binding land use regulation, the per $m^{2}$ price of land is a direct function of the local amenities and the restrictiveness of the regulations. The maximum $F A R_{\max }$ regulation, which is a common regulatory instrument in the study area, is a very tractable and economic interpretable measure. We formulate a simple model that emphasizes the best land use assumption, i.e., the optimal exploitation of the land under regulation. We show that an additional unit of apartment surface requires $1 / F A R_{\max }$ units of land. Moreover, for a constant $F A R_{\max }$, it can be shown that the marginal price for the apartment size has three rent components: the presumably constant rents for structure and physical land, as well as the land-rent inherent location value.

In the case of binding $F A R_{\max }$, the interaction of locations with lot size under best use is a promising approach to determine land price variations from land rents. We therefore formulate a theoretical model in which the potential apartment rent is capitalized into land values. We then show empirically how to use apartment rent data to determine per $m^{2}$ land prices. Applying the model to a hedonic setting based on an extensive sample of rental data in the canton of Zurich, we estimated local residential land values. The transformation of rent components into land prices is a linear function, which includes the capitalization rate as a coefficient.

We demonstrated that our model is highly reliable in predicting land prices. In particular, the correlation coefficient between predicted values and observed land prices is 0.947, and the relative prediction error is $18.9 \%$. This high prediction accuracy makes the model suitable for practical application. For instance, it provides a basis for predicting 
land values in places where land transactions are infrequent or even absent. This is particularly good news since land transactions tend to be low in urban areas, where rent observations are very frequent. A comparison of the model with a benchmark (location dummy model) demonstrates that it is superior in explaining spatial land price variations.

As a by-product of the goodness-of-fit test of our model, we estimated a capitalization rate of $7.63 \%$. This finding is interesting from an asset pricing perspective. Particularly, it can serve as a benchmark capitalization rate for residential real estate investments. However, the derived return on investment cannot be compared to capitalization rates used for real estate appraisal purposes, because it is a gross rate and is associated with the location only.

In a final step, we utilized our findings from the model test to estimate a land value surface. The number of observations allowed us to use a non-parametric approach to predict land values for any location. Concentrating on the larger urban area around the city of Zurich, we found a monocentric pattern in the predicted land values. This monocentricity is the result of two main sources affecting the urban spatial structure: First, the monocentric location value pattern is the result of higher amenities in central locations. Second, the monocentric land quality pattern is the result of land use regulation, i.e., the result of the higher permitted floor area ratios in central areas. Thus, when estimating land values, and especially, when the location values stem from regression residuals, land quality should be accounted for. 


\section{Appendix}

\section{Table A.1: Data Description}

This table shows the apartment characteristics of rental dwellings for the canton of Zurich by category, i.e., by rental price, structure, location, and time. The data set contains more than 40,000 observations provided by a multiple listing service (MLS) for apartment offerings from 2002 to 2014.

\begin{tabular}{lll}
\hline \hline Category & Variable & Description \\
\hline Rental price & Rental price & Gross rental price in Swiss Francs per month \\
& Area & Living area of the apartment in $m^{2}$ \\
& Rooms & Number of rooms. Living rooms counting for 1.5 rooms \\
Special view & Binary variable, indicating whether the apartment has special view \\
Lift & Binary variable, indicating whether the apartment has a lift \\
Parking & Binary variable, indicating whether the apartment \\
& offers a parking opportunity \\
& Garage & Binary variable, indicating whether the apartment \\
& Ap_Standard & Bas a parking garage space \\
& Ap_Duplex & Binary variable, indicating whether it is a standard apartment \\
Ap_Attic & Binary variable, indicating whether it is a penthouse apartment \\
Ap_Roof & Binary variable, indicating whether it is a roof apartment \\
Ap_Studio & Binary variable, indicating whether it is a studio apartment \\
Ap_OneRoom & Binary variable, indicating whether it is a one room apartment \\
Ap_Furnished & Binary variable, indicating whether the apartment is furnished \\
Ap_Terrace & Binary variable, indicating whether the apartment has a terrace \\
Ap_InHome & Binary variable, indicating whether it is an apartment \\
& Ap_Loft & Bithin a single-family detached home \\
Time & Address & Street address of the apartment \\
Availability & Date of availability of the apartment \\
\hline \hline
\end{tabular}


Table A.2: Regions (Jurisdictions) in the Canton of Zurich

This table lists the 171 communes of the canton of Zurich.

\begin{tabular}{|c|c|c|c|c|c|c|c|}
\hline ID & Name & ID & Name & ID & Name & ID & Name \\
\hline 1 & Aeugst a.A. & 56 & Embrach & 115 & Gossau & 192 & Egg \\
\hline 2 & Affoltern a.A. & 57 & Freienstein-Teufen & 116 & Grüningen & 193 & Fällanden \\
\hline 3 & Bonstetten & 58 & Glattfelden & 117 & Hinwil & 194 & Greifensee \\
\hline 4 & Hausen a.A. & 59 & Hochfelden & 118 & Rüti & 195 & Maur \\
\hline 5 & Hedingen & 60 & Höri & 119 & Seegräben & 196 & Mönchaltorf \\
\hline 6 & Kappel a.A. & 61 & Hüntwangen & 120 & Wald & 197 & Schwerzenbach \\
\hline 7 & Knonau & 62 & Kloten & 121 & Wetzikon & 198 & Uster \\
\hline 8 & Maschwanden & 63 & Lufingen & 131 & Adliswil & 199 & Volketswil \\
\hline 9 & Mettmenstetten & 64 & Nürensdorf & 132 & Hirzel & 200 & Wangen-Brüttisellen \\
\hline 10 & Obfelden & 65 & Oberembrach & 133 & Horgen & 211 & Altikon \\
\hline 11 & Ottenbach & 66 & Opfikon & 134 & Hütten & 212 & Bertschikon \\
\hline 12 & Rifferswil & 67 & Rafz & 135 & Kilchberg & 213 & Brütten \\
\hline 13 & Stallikon & 68 & Rorbas & 136 & Langnau a.A. & 214 & Dägerlen \\
\hline 14 & Wettswil a.A. & 69 & Wallisellen & 137 & Oberrieden & 215 & Dättlikon \\
\hline 21 & Adlikon & 70 & Wasterkingen & 138 & Richterswil & 216 & Dinhard \\
\hline 22 & Benken & 71 & Wil & 139 & Rüschlikon & 217 & Elgg \\
\hline 23 & Berg a.I. & 72 & Winkel & 140 & Schönenberg & 218 & Ellikon a.d.Th. \\
\hline 24 & Buch a.I. & 81 & Bachs & 141 & Thalwil & 219 & Elsau \\
\hline 25 & Dachsen & 82 & Boppelsen & 142 & Wädenswil & 220 & Hagenbuch \\
\hline 26 & Dorf & 83 & Buchs & 151 & Erlenbach & 221 & Hettlingen \\
\hline 27 & Feuerthalen & 84 & Dällikon & 152 & Herrliberg & 222 & Hofstetten \\
\hline 28 & Flaach & 85 & Dänikon & 153 & Hombrechtikon & 223 & Neftenbach \\
\hline 29 & Flurlingen & 86 & Dielsdorf & 154 & Küsnacht & 224 & Pfungen \\
\hline 30 & Andelfingen & 87 & Hüttikon & 155 & Männedorf & 225 & Rickenbach \\
\hline 31 & Henggart & 88 & Neerach & 156 & Meilen & 226 & Schlatt \\
\hline 32 & Humlikon & 89 & Niederglatt & 157 & Oetwil a.S. & 227 & Seuzach \\
\hline 33 & Kleinandelfingen & 90 & Niederhasli & 158 & Stäfa & 228 & Turbenthal \\
\hline 34 & Laufen-Uhwiesen & 91 & Niederweningen & 159 & Uetikon a.S. & 229 & Wiesendangen \\
\hline 35 & Marthalen & 92 & Oberglatt & 160 & Zumikon & 230 & Winterthur \\
\hline 36 & Oberstammheim & 93 & Oberweningen & 161 & Zollikon & 231 & Zell \\
\hline 37 & Ossingen & 94 & Otelfingen & 171 & Bauma & 241 & Aesch \\
\hline 38 & Rheinau & 95 & Regensberg & 172 & Fehraltorf & 242 & Birmensdorf \\
\hline 39 & Thalheim a.d.Th. & 96 & Regensdorf & 173 & Hittnau & 243 & Dietikon \\
\hline 40 & Trüllikon & 97 & Rümlang & 174 & Illnau-Effretikon & 244 & Geroldswil \\
\hline 41 & Truttikon & 98 & Schleinikon & 175 & Kyburg & 245 & Oberengstringen \\
\hline 42 & Unterstammheim & 99 & Schöfflisdorf & 176 & Lindau & 246 & Oetwil a.d.L. \\
\hline 43 & Volken & 100 & Stadel & 177 & Pfäffikon & 247 & Schlieren \\
\hline 44 & Waltalingen & 101 & Steinmaur & 178 & Russikon & 248 & Uitikon \\
\hline 51 & Bachenbülach & 102 & Weiach & 179 & Sternenberg & 249 & Unterengstringen \\
\hline 52 & Bassersdorf & 111 & Bäretswil & 180 & Weisslingen & 250 & Urdorf \\
\hline 53 & Bülach & 112 & Bubikon & 181 & Wila & 251 & Weiningen \\
\hline 54 & Dietlikon & 113 & Dürnten & 182 & Wildberg & 261 & Zürich \\
\hline 55 & Eglisau & 114 & Fischenthal & 191 & Dübendorf & & \\
\hline
\end{tabular}




\section{Figure A.1: Vacancy Rates}

This figure illustrates the vacancy rate of apartments in communes of the canton of Zurich. Out of the 171 communes, more than half have a vacancy rate for apartments of less than $1 \%$. The overall average is $0.61 \%$

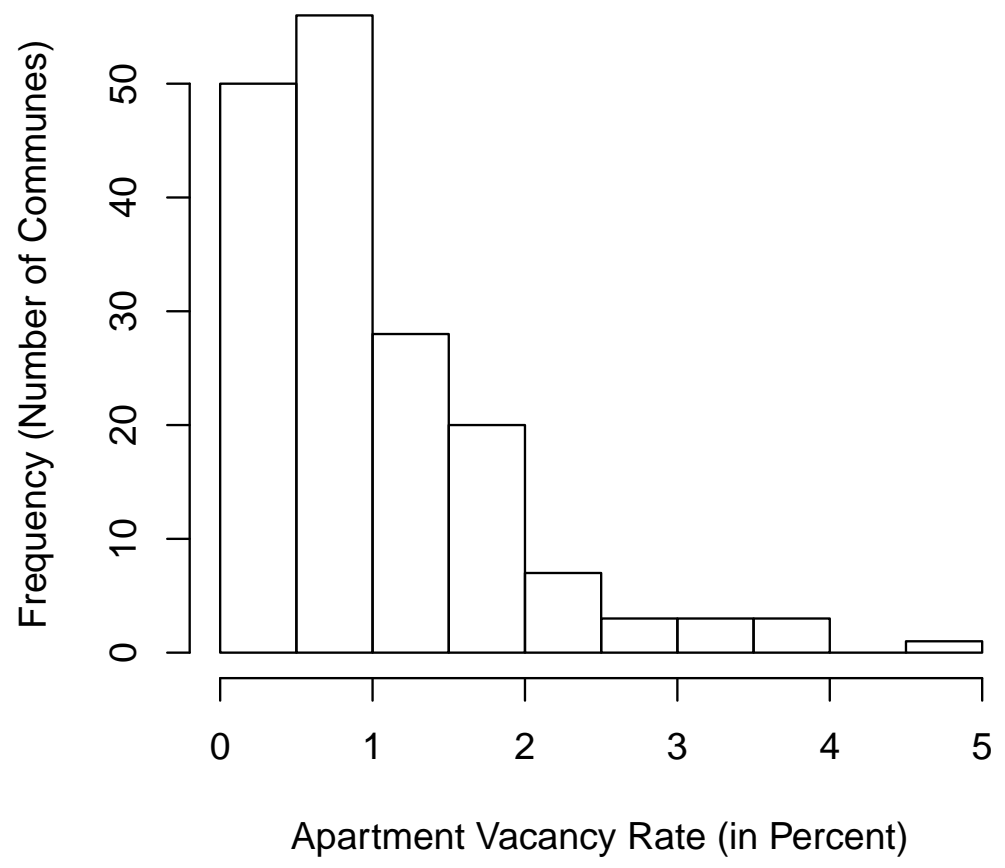


Figure A.2: $R^{2}$ as a Function of the Negative Externality Parameter

This figure illustrates the development of the goodness-of-fit of the overall regression in terms of $R^{2}$ derived from Equation (15) based on various levels of the global negative externality parameter, $\rho$. With a negative externality parameter of 0.65 , the effect of the $F A R$ on land prices is decreasing. The graph demonstrates the negative externalities of the FAR.

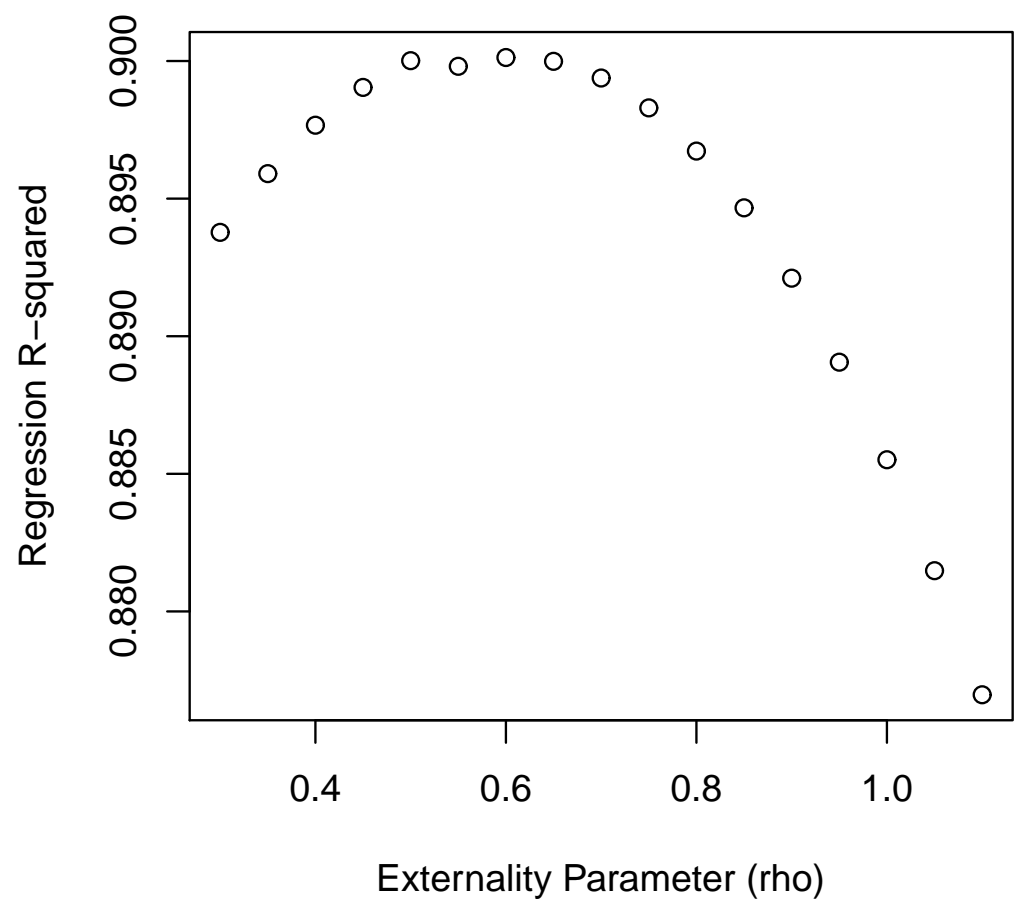




\section{References}

Alonso, W. (1964): Location and Land Use. Toward a general theory of land rent. Harvard University Press.

Barr, J., And J. P. Cohen (2014): "The Floor Area Ratio Gradient: New York City, 1890-2009," Regional Science and Urban Economics, 48, 110-119.

BFS Strukturerhebung (2012): "Strukturerhebung des Jahres 2012," Electronic data available at http://www.bfs.admin.ch/, Bundesamt für Statisik.

Cheshire, P., and S. Sheppard (1995): "On the Price of Land and the Value of Amenities," Economica, 62(246), 247-267.

Chichernea, D., N. Miller, J. Fisher, M. Sklarz, and B. White (2008): "A cross-sectional analysis of cap rates by MSA," Journal of Real Estate Research, 30(3), 249-292.

Clapp, J. M., and Y. WAng (2006): "Defining Neighborhood Boundaries: Are Census Tracts Obsolete?," Journal of Urban Economics, 59(2), 259-284.

Coulson, N. E. (1991): "Useful Tests of the Monocentric Model," Land Economics, $67(3), 299-307$.

Fik, T. J., D. C. Ling, And G. F. Mulligan (2003): "Modeling Spatial Variation in Housing Prices: A Variable Interaction Approach," Real Estate Economics, 31(4), $623-646$.

Füss, R., AND J. A. Koller (2016): "The role of spatial and temporal structure for residential rent predictions," International Journal of Forecasting, 32(4), 1352-1368.

Gyourko, J., A. Saiz, and A. Summers (2008): "A new measure of the local regulatory environment for housing markets," Urban Studies, 45(3), 693-721.

HAmmel, D. (1999): "Re-establishing the rent gap: an alternative view of capitalised land rent," Urban Studies, 36(8), 1283-1293.

IHLANFELDT, K. (2007): "The effect of land use regulation on housing and land prices," Journal of Urban Economics, 61(3), 420-435.

Joshi, K. K., and T. Kono (2009): "Optimization of Floor Area Ratio Regulation in a Growing City," Regional Science and Urban Economics, 39(4), 502-511. 
Kok, N., P. Monkkonen, and J. Quigley (2014): "Land use regulations and the value of land and housing: An intra-metropolitan analysis," Journal of Urban Economics, 81, 136-148.

Kolbe, J., R. Schulz, M. Wersing, and A. Werwatz (2012): "Location, Location, Location: Extracting Location Value from House Prices," Discussion Papers of DIW Berlin 1216, DIW Berlin, German Institute for Economic Research.

Kubli, U., A. Lüscher, M. Salvi, P. Schellenbauer, J. Schellenberg, P. Moser, U. Rey, and C. Bischoff (2008): "Wertvoller Boden," Discussion paper, Zürcher Kantonalbank und Statistisches Amt des Kantons Zürich.

Malpezzi, S. (2013): "Population Density: Some Facts and Some Predictions," Cityscape, 15(3), 183-201.

Miles, D. (2012): "Population Density, House Prices and Mortgage Design," The Scottish Journal of Political Economy, 59(5), 444-466.

Mills, E. S. (1967): "An aggregative model of resource allocation in a metropolitan area," The American Economic Review, 57(2), 197-210.

Mulder, C. H. (2006): "Population and Housing: A Two-sided Relationship.," Demographic Research, 13(13), 401-412.

Muth, R. F. (1969): Cities and Housing. University of Chicago Press.

OoI, J., And S.-T. LeE (2004): "Price Discovery between Residential Land \& Housing Markets," Journal of Housing Research, 15(2), 95-112.

Parsons, G. R. (1990): "Hedonic Prices and Public Goods: An argument for Weighting Locational Attributes in Hedonic Regressions by Lot Size," Journal of Urban Economics, 27(3), 308-321.

Quigley, J., And L. Rosenthal (2008): "The Effects of Land Regulation on the Price of Housing What Do We Know? What Can We Learn?," Cityscape, 8(1), 69-137.

Rossi-Hansberg, E., P.-D. Sarte, and R. Owens (2010): "Housing Externalities," Journal of Political Economy, 118(3), 485-535.

SAIZ, A. (2010): "The geographic determinants of housing supply," Quarterly Journal of Economics, 125(3), 1253-1296. 
Sivitanides, P., J. Southard, R. G. Torto, and W. C. Wheaton (2001): "The determinants of appraisal-based capitalization rates," Real Estate Finance, 18(2), 27 38.

Smith, N. (1979): "Toward a Theory of Gentrification - A Back to the City Movement by Capital, not People," Journal of the American Planning Association, 45(4), 538-548.

Statistisches Amt Des Kantons Zürich (2014): "Anzahl Transaktionen und Preise von unbebautem Wohnland seit 1990," Electronic data available at http://www.statistik.zh.ch/, Kanton Zürich, Direktion der Justiz und des Innern.

Wheaton, W. C. (1998): "Land Use and Density in Cities with Congestion," Journal of Urban Economics, 43(2), 258-272. 
Tables 


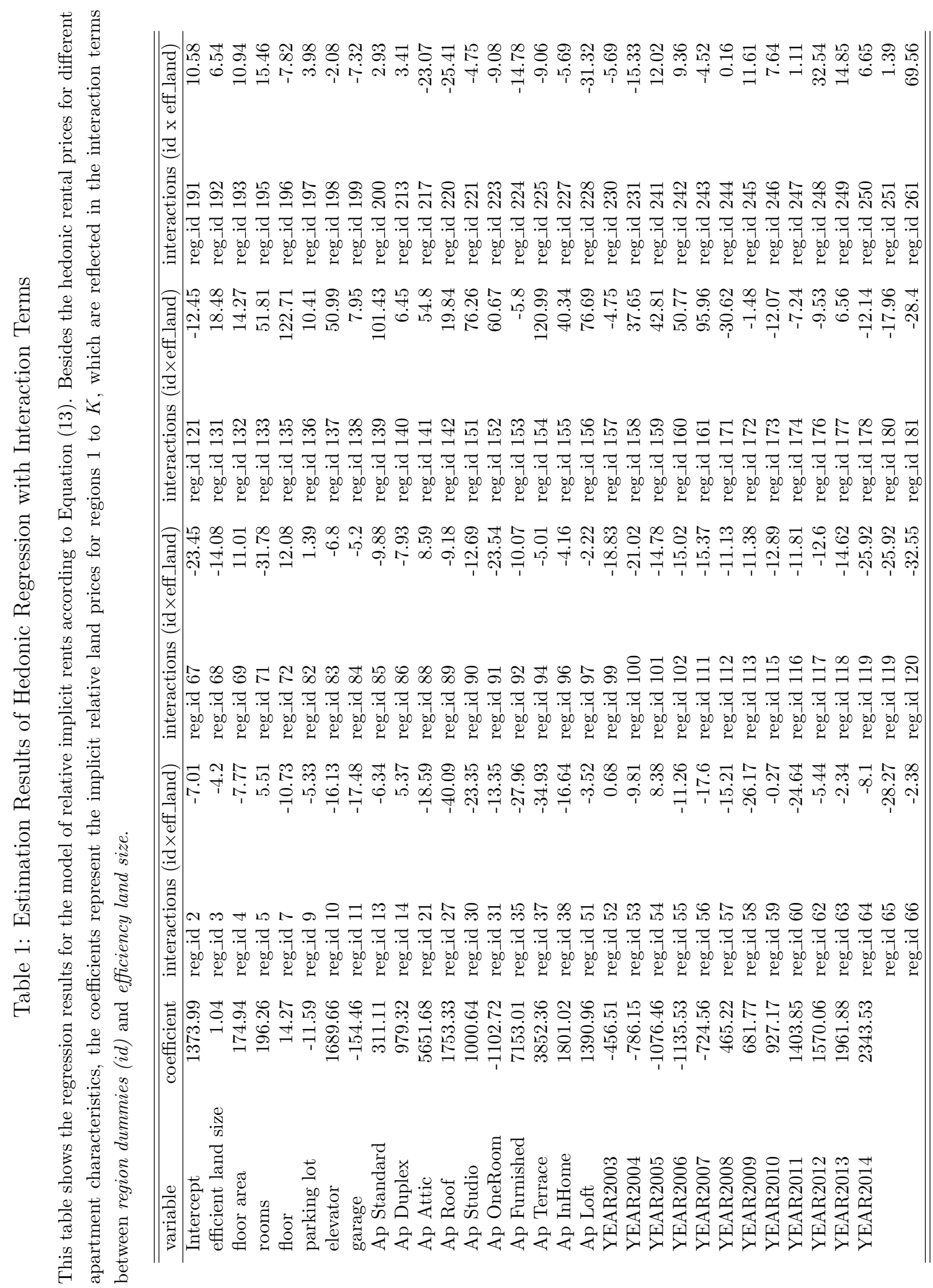


Table 2: Regression Results for Land Price Prediction

This table shows the regression results of regional (aggregated) average land prices on implicit relative land rents for the regions. Unadjusted standard errors are shown in parentheses. The number of observations is $N=72$. MRE stands for mean relative error. The capitalization rate (cap-rate) is the inverse of the slope. These figures are estimated for different sub-periods (columns (2) to (4)) as well as for the whole time period from 2002 to 2014 (column (5)). The capitalization rate decreases over the three sub-periods from $10.38 \%$ (2002-2005) to $5.68 \%$ (2010-2014).

\begin{tabular}{|c|c|c|c|c|c|}
\hline Model & \multicolumn{4}{|c|}{ Interaction Model } & Dummy Model \\
\hline Year & $2002-2005$ & 2006-2009 & $2010-2014$ & $2002-2014$ & $2002-2014$ \\
\hline Intercept & $740.42(14.04)$ & $847.22(14.14)$ & $865.16(31.39)$ & 718.77 (11.97) & 658.89 (12.99) \\
\hline Slope & $9.638(0.52)$ & $13.609(0.45)$ & $17.603(0.91)$ & $13.11(0.41)$ & 0.109 \\
\hline$R^{2}$ & 0.745 & 0.889 & 0.799 & 0.894 & 0.878 \\
\hline$M R E$ & 0.190 & 0.172 & 0.254 & 0.136 & 0.160 \\
\hline cap-rate & $10.38 \%$ & $7.35 \%$ & $5.68 \%$ & $7.63 \%$ & - \\
\hline
\end{tabular}




\section{Figures}

Figure 1: Short- and Long-Term Demand for Floor Area

This figure shows the relationship between the price and quantity of land. In a homogeneous, regional housing market the short-term demand for residential floor is assumed to be unit elastic, while the longterm demand is perfectly elastic. The introduction of negative externalities by accounting for the price elasticity of land with respect to the maximum allowed floor area ratio $(F A R)$ affects the long-term demand negatively. It follows that a change in the $F A R$ directly capitalizes into land values due to its decreasing marginal effect.

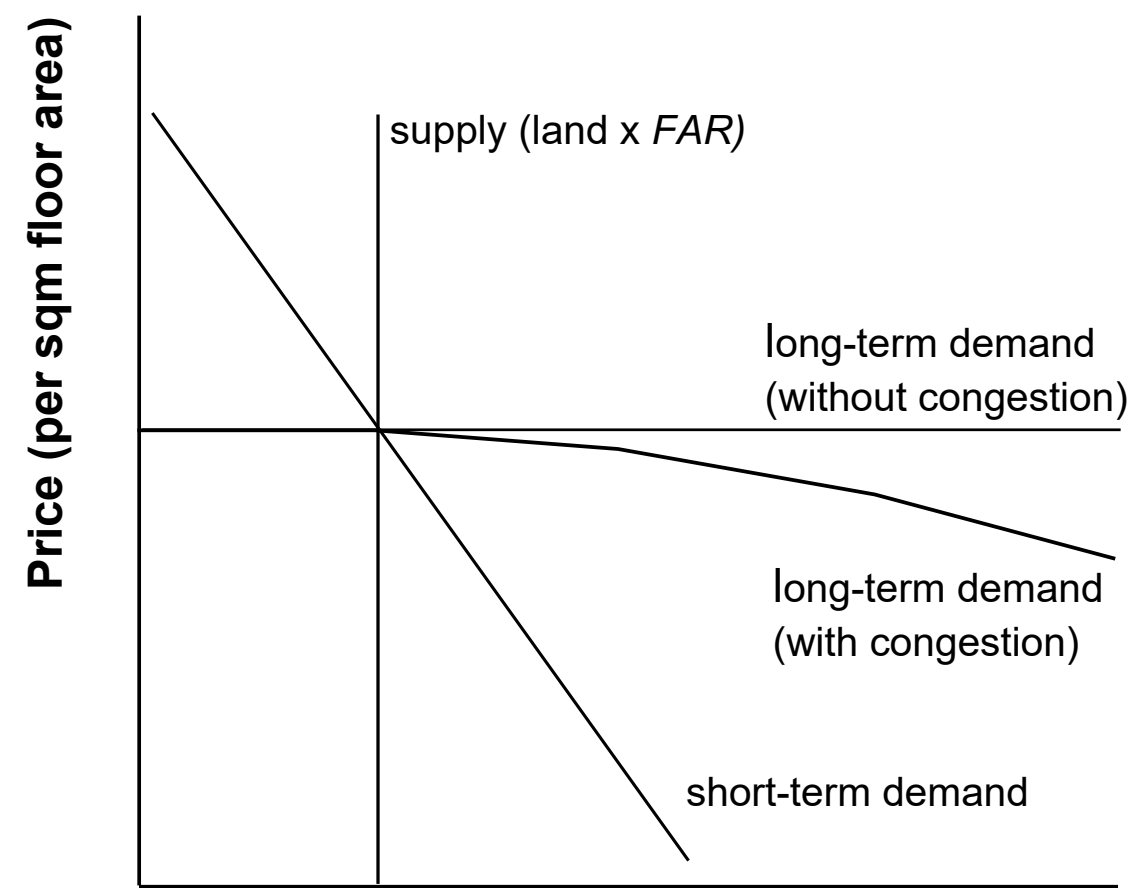

Quantity (land x FAR) 
Figure 2: Map of Canton of Zurich

This figure shows the spatial dispersion of rental price observations for the canton of Zurich. The light and dark colored dots represent low and high rents in the data sample, respectively. The solid shapes of the map indicate the 171 communes within the canton's boundaries. The dispersion of observations corresponds to the variation in residents, with $36 \%$ of the observations coming from Zurich (largest city) and Winterthur (second largest city). The total population of the canton of Zurich amounts to approximately $1.4 \mathrm{~m}$ at the end of 2013 .

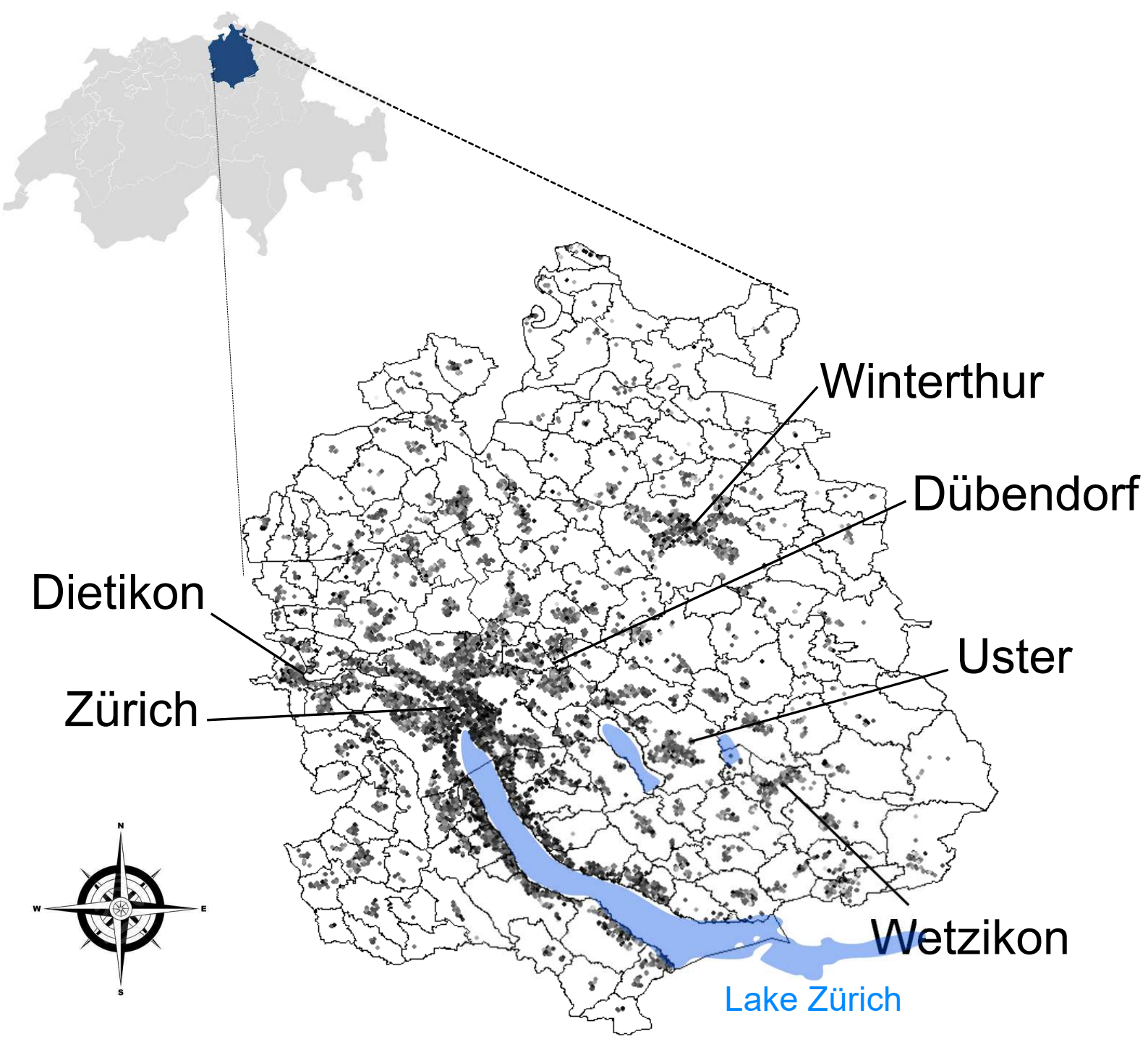


Figure 3: Predicted versus Observed Land Transaction Prices

This figure compares the implicit relative land rents to the observed absolute mean land prices of the canton of Zurich. The predicted implicit relative land prices are the fitted values based on the estimation results from Table 1 in the Appendix. The strong linear relationship between the predicted and actual land prices is reflected in a correlation coefficient of 0.904 .

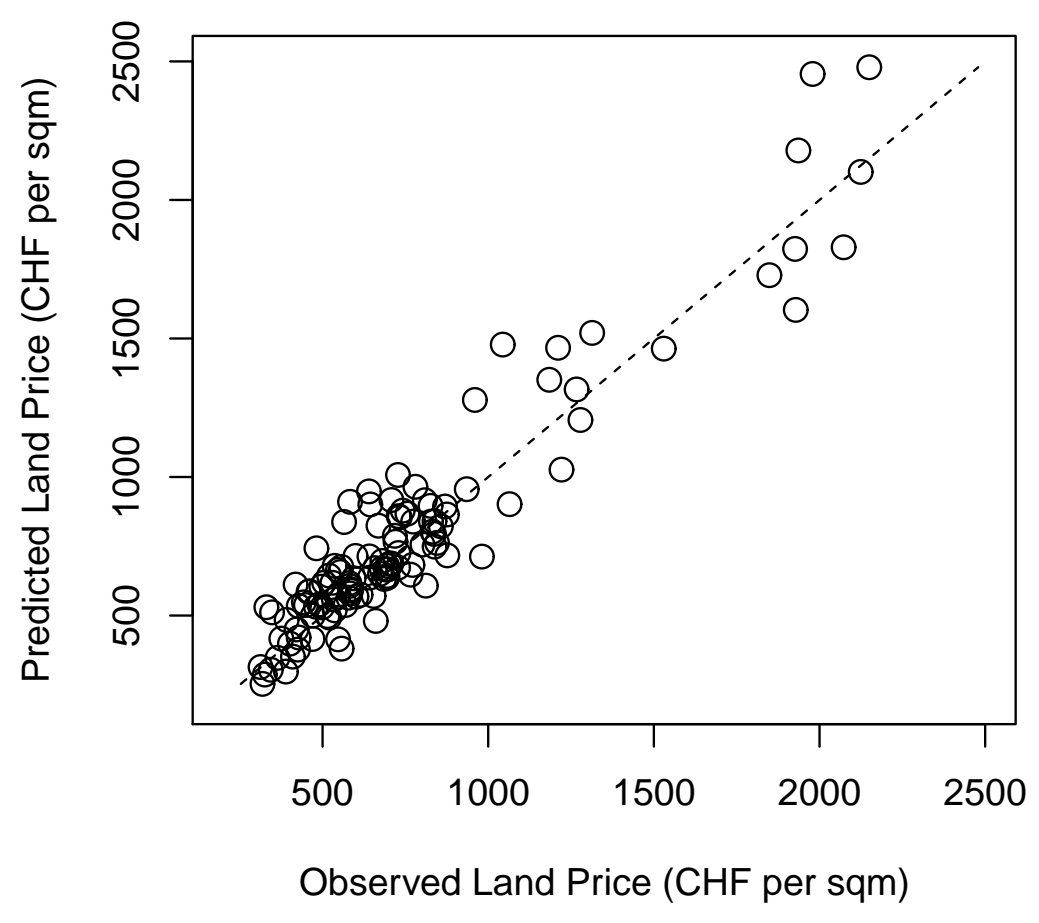


Figure 4: Non-parametric Estimates of Predicted Land Values

This figure shows the estimation results for the land value surface based on smoothed predicted (implicit) land values. In the non-parametric local regression, land price predictions are regressed on the longitude and latitude. The estimation is based on the Nadaraya-Watson local constant estimator. The isolines correspond to land value estimates. Note that the Nadaraya-Watson estimates, which are located close to the boundary and outside the map, are not consistent and do not allow for an economic interpretation.

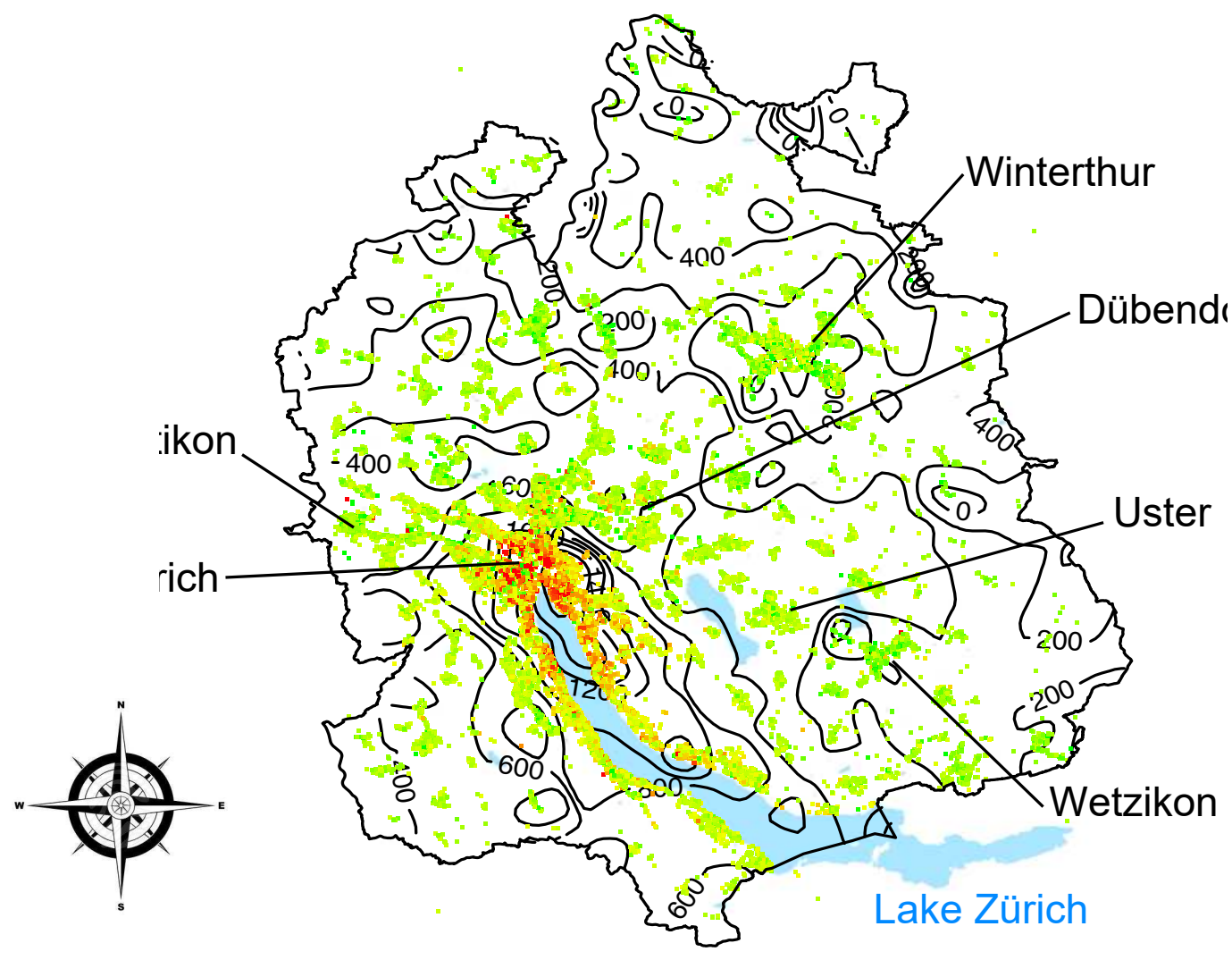


Figure 5: Non-parametric Estimates of Location Value and Land Quality

This figure shows the non-parametric surface of the location value in the left-hand side graph, while the right-hand side graph shows the land quality measured in terms of the floor area ratio $(F A R)$. The location value reflects the central location's attractiveness with the highest value in the CBD, from which location prices decrease in all directions. Because of higher $F A R \mathrm{~s}$ in central areas, land prices increase in the CBD accordingly.

Floor Area Ratio (city of Zurich)

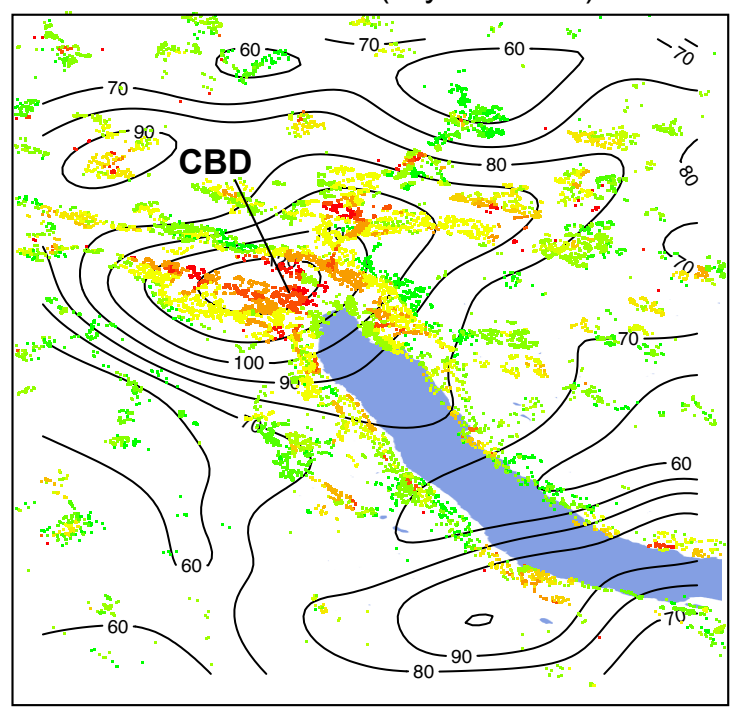

Location value (city of Zurich)

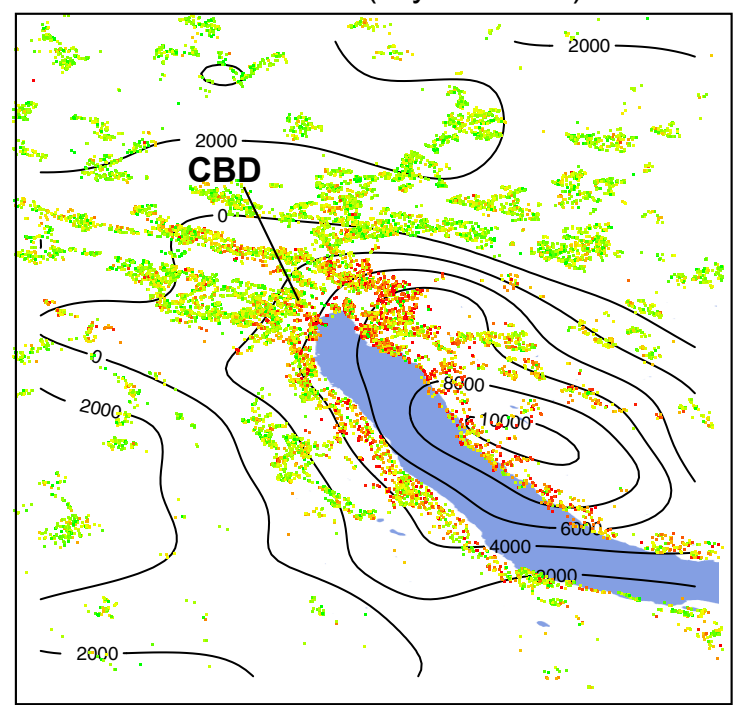


Figure 6: Non-parametric Estimates of Predicted Land Values

This figure shows the predicted land values as the product of location quality and land quality. The oval gradients of land prices reflect the monocentric structure of land quality in the larger area of the city of Zurich. High location values can be observed along the lakeside as well as more in the north next to the lake, i.e., high floor area ratios reflect high local amenities.

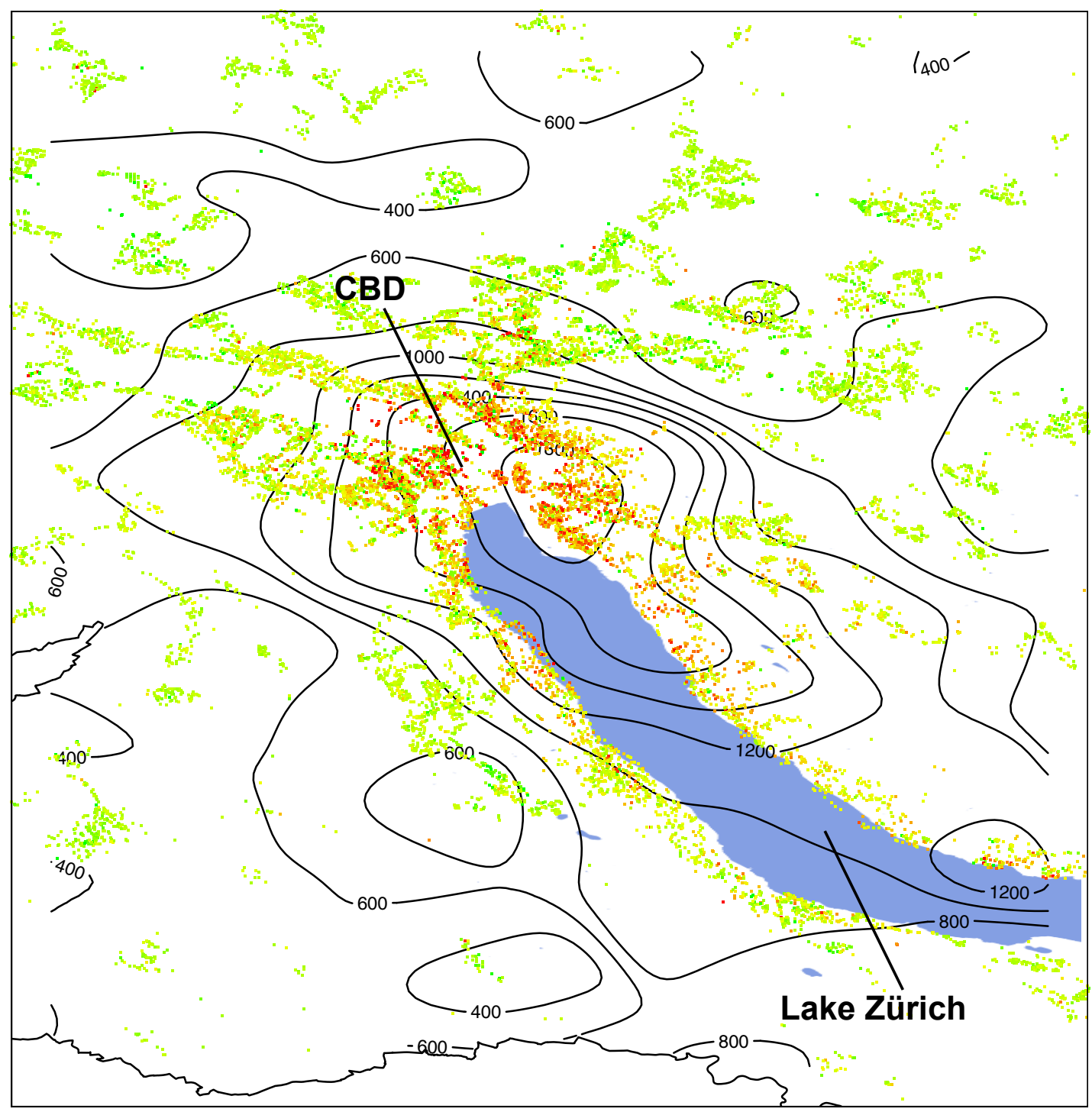

